\title{
Informação, memória e ciberespaço: considerações preliminares no campo da Ciência da Informação no Brasil
}

\author{
Information, memory and cyberspace: Preliminary \\ observations in the field of Information \\ Science in Brazil
}

\author{
Fabiana Aparecida LAZZARIN ${ }^{1}$ \\ Carlos Xavier de AZEVEDO NETTO' \\ Marckson Roberto Ferreira de SOUSA'
}

\begin{abstract}
Resumo
O presente trabalho discute a relação entre informação e memória dentro da esfera do ciberespaço, considerando-se que este se mostra um ambiente multimodal, caracterizado por atualização frequente de informações. Esta pesquisa busca identificar, através de autores da área de Ciência da Informação, possíveis barreiras que vêm suplantando a memória no ambiente virtual. Para alcançar tal objetivo, fez-se uso de uma revisão bibliográfica no campo empírico, nas fontes dos trabalhos apresentados nos encontros da Associação Nacional de Pesquisa e Pós-Graduação em Ciência da Informação, nos anos de 2010 e 2011, especificamente no Grupo de Trabalho 10 - Informação e Memória. Foram analisados setenta trabalhos, dos quais somente treze trataram das temáticas informação, memória e ciberespaço. Por meio dessas análises, constataram-se algumas inquietações por parte dos autores, as quais podem representar possíveis problemas para a suplantação da memória existente no ciberespaço: a tensão existente entre lembrança e esquecimento e a veracidade das informações dis-seminadas.
\end{abstract}

Palavras-chave: Ciberespaço. Informação. Memória.

\begin{abstract}
The aim of this paper is to discuss the relationship between information and memory within the realm of cyberspace, considering that cyberspace is a multimodal environment characterized by the frequent updating of information. Based on authors in the field of Information Science, the present research seeks to identify potential problems that have been superseding the memory in the virtual environment. To achieve our goal, we conducted a review of the empirical literature between 2010 and 2011 using papers presented at the meetings of the National Association for Research and Graduate Studies in Information Science, particularly those in the Working Group 10: Information and Memory. We analyzed seventy papers of which only thirteen addressed the following issues: information, memory and cyberspace. After the analysis, it appears that some of the authors' concerns related to the potential problems of supersession of the existing memory in cyberspace are: tension between remembering and forgetting, and the veracity of disseminated information.
\end{abstract}

Keywords: Cyberspace. Information. Memory.

\footnotetext{
1 Universidade Federal da Paraíba, Departamento de Ciência da Informação, Programa de Pós-Graduação em Ciência da Informação. Campus Universitário I, Jd. Cidade Universitária, 58059-900, João Pessoa, PB, Brasil. Correspondência para/Correspondence to: F.A. LAZZARIN. E-mail:<fabilazzarin@yahoo.com.br>. Recebido em 9/9/2013, reapresentado em 25/2/2014 e aceito para publicação em 24/3/2014.
} 


\section{Introdução}

As discussões, científicas ou não, sobre os limites e o conceito de informação não são recentes. Nesse sentido, vincula-se uma série de acontecimentos com referências muitas vezes históricas, que apontam diversas disciplinas que entendem a informação como seu objeto de estudo. Para isso, diversos campos do conhecimento tentam fincar suas raízes e delimitar seus espaços epistemológicos na busca incansável de se firmar enquanto ciência.

De acordo com o pensamento de Souza (2008), os estudos desenvolvidos nas últimas décadas sobre o fenômeno da informação, particularmente no campo da Ciência da Informação (Cl), têm suscitado alguns questionamentos sobre a consistência de sua base teórico-metodológica e, consequentemente, sobre o alcance da validade dos resultados deles advindos.

Considerando a abrangência dessa discussão, Pacheco (1995) busca estabelecer um diálogo contextualizado com o leitor, não como uma forma de apresentar definições fechadas sobre o conceito de informação, mas sim na tentativa de criar um cenário para que através dele obtenha-se uma visão da informação considerada como artefato, no sentido de ser um produto de confecção humana. Ainda segundo a referida autora, o século XX assumiu uma peculiaridade frente às sociedades de economia capitalista, com o aprimoramento das redes de telecomunicação e em decorrência da explosão no consumo de bens descartáveis. Um produto tomou o lugar central nesse novo cenário, em que a principal característica desse produto - fluido e transitório, de crescimento vertiginoso e que se acumula no tempo e espaço, como disse Mikailov (1984) - tem sido a velocidade com que é gerada, consumida e descartada a informação.

A tendência desenfreada do homem em abarcar todos os assuntos com uma maior facilidade de acesso, sejam eles os mais distintos possíveis, tem sido pauta de discussão de pesquisadores, nas mais diversas áreas do conhecimento, que dedicam esforços redobrados na tentativa de compreender o que hoje se chama de "explosão informacional". De acordo com Bawden e Robinson (2009), a transição para o digital - ao considerar o movimento em direção a uma situação em que a informação profissional e acadêmica se torna cada vez mais significativa, estando aliada à tendência de utilização crescente da Internet e mais especificamente da World Wide Web, a partir da década de 1990 - fez com que houvesse uma expansão das informações disponíveis, acarretando uma sobrecarga de informação.

Para Braga, esse excesso de informação é denominado "neurose do século XXI" (Braga, 2006, online) e, para Wurman (2005), "ansiedade de informação". O ponto de convergência entre uma nomenclatura e outra está no fato de haver informação em excesso, resultando, segun-do Wurman (2005, p.14), em uma "[...] distância cada vez maior entre o que compreendemos e o que achamos que deveríamos compreender".

Considerando os estudos de Zeman (1970) em um contexto científico em que estava vigente a era da Teoria Matemática, na qual a informação estava ligada apenas à quantificação como uma forma de medida de transferência, é possível perceber que o processo de aquisição da informação está ligado ao tempo e que em cada situação particular só é possível obter, durante certo tempo, uma quantidade máxima limitada de informação, destacando-se que esta não é um termo exclusivamente matemático, mas também filosófico, pois está ligado à qualidade.

É interessante notar a característica particular que Zeman (1970) e posteriormente Pacheco (1995) atribuem ao artefato informação, apontando que ela é espacial, temporal e morfologicamente contextualizada, e que essa contextualização não é obra de um acaso estatístico. Com essa linha de pensamento, Pacheco demonstra a independência dos registros produzidos pelo homem, concluindo que a informação enquanto artefato passa a ser um produto de confecção humana, cultural e socialmente aceito, sem existência própria na natureza, passando a ser percebida e estabelecida quando é criada uma relação de significação. Para Azevedo Netto (2007, p.13) uma das formas de se perceber a informação contida nos artefatos pode ser chamada de informação relacional:

Esse tipo de informação está contido na especificidade das variações espacial e temporal, detectadas dentro da distribuição dos signos. Tais variações são observadas a partir das afinidades estruturais e formais, somadas à da organização 
discursiva, sempre referendada pela especificidade de código de cada unidade cultural considerada.

A tentativa de compreensão do território circunstancial do construto informação pode orientar os aspectos teóricos de memória, tanto como registro da informação no ambiente virtual, quanto como recurso de (re)construção de uma memória social. Trava-se uma luta entre a dualidade informação e alienação do cérebro humano, com a consequentemente dificuldade de se conservar a memória de todas as ideias, fatos e acontecimentos que mais interessam ao indivíduo. Para Pacheco (1995, p.22),

A facilidade do acesso à informação está suplantando a memória. Hoje em dia os esforços são redobrados na tentativa de livrar o homem do esforço de lembrar. O que importa não é mais conhecer, mas sim ter meios e instrumentos rápidos para acessar o conhecimento. Os bancos de dados se transformaram em gigantescos supermercados [...], o que esses 'supermercados cibernéticos' vendem mais são as fórmulas prontas de preparo instantâneo e consumo imediato. Ou seja, o produto, o artigo, o artefato informação, como concebido nos dias de hoje, se destaca mais por suas características físicas, que são na realidade as características de seu suporte, do que por suas características sociais, de tal forma que essa informação não pode mais ser armazenada no cérebro humano.

Diante desse contexto que afeta diretamente as áreas do conhecimento que trabalham com a informação, esta pesquisa busca compreender as relações existentes entre informação e memória no ciberespaço, com o intuito de identificar, através de autores da área da $\mathrm{Cl}$, possíveis barreiras que vêm suplantando a memória no ambiente virtual.

Assim, vale ressaltar que a compreensão sobre memória, neste estudo, está apoiada diretamente segundo o foco de Azevedo Netto (2008, p.12), que

Entende por memória aquele conjunto de eventos, fatos, personagens que, através da sua existência no passado, possuem experiências consistentes para o estabelecimento de uma relação da atualidade e o seu passado, quer imediato quer remoto [...] A noção de memória está transpassada por um universo simbólico dos mais significativos, mediante um processo de representação no qual são criados referentes para sua cristalização nas consciências, quer individuais quer coletivas, aproximando-a, em muito, da noção de identidade.

Para alcançar o objetivo proposto, é importante destacar que se fará uso de uma revisão bibliográfica no campo empírico, nas fontes dos trabalhos apresentados nos encontros da Associação Nacional de Pesquisa e Pós-Graduação em Ciência da Informação (ANCIB), nos anos de 2010 e 2011, período em que foi introduzido o Grupo de Trabalho (GT) 10 - Informação e Memória². Embora sem pretensão de esgotar o tema, ressalta-se que esse espaço empírico ajudará a mapear, em nível nacional, na área de $\mathrm{Cl}$, como estão sendo trabalhadas as questões de informação e memória no ambiente virtual, quais os principais autores que discutem a temática, se em suas considerações há problemas relacionados à memória no ciberespaço e quais são eles.

\section{Reflexão sobre informação, memória e ciberespaço}

Quando se pensa em informação e conhecimento no século XXI, logo se incorpora esse pensamento à comunicação e à linguagem digital como um dos requisitos essenciais para a formação dos cidadãos na atual sociedade. As tecnologias voltadas para os processos de globalização trazem em si dois movimentos distintos, a rarefação e a reafirmação, no que diz respeito às questões de memória coletiva e identidade cultural. Conforme o pensamento de Le Goff (2003), a rarefação se dá pela ruptura das fronteiras nacionais, economicamente estabelecidas, enquanto o outro movimento é marcado pela reafirmação das identidades culturais locais, em busca do equilíbrio desfeito pela rarefação.

Os indivíduos que constituem a classe dominante, como produtores de ideias, determinam a maneira de pensar do grupo, na medida em que dominam enquanto

\footnotetext{
2 O GT 10 aborda estudos sobre a relação entre os campos de conhecimento da Ciência da Informação e da Memória Social. O Grupo desenvolve pesquisas transdisciplinares que envolvem conceitos, teorias e práticas do binômio informação e memória, nos seguintes campos: Memória coletiva, coleções e colecionismo, discurso e memória; Representações sociais e conhecimento; Articulação entre arte, cultura, tecnologia, informação e memória, através de seus referencias, na contemporaneidade; Preservação e virtualização da memória social.
} 
classe. As suas ideias são, portanto, dominantes em sua época (Marx \& Engels, 2006). Pode-se afirmar que o segmento social que tem o poder informacional dominante numa dada sociedade é aquele que irá possuir o poder de controle sobre essa sociedade, podendo interferir, dessa forma, na questão da memória coletiva.

Conforme Habermas (1993, p.91), fiel às suas origens marxistas,

o sistema social está ligado ao modo pelo qual as estruturas sociais constrangem as ações dos indivíduos; está ligado, portanto, às questões de poder e, em específico, às relações de classe que envolvem produção. O mundo da vida, por outro lado, está ligado às questões de significado e comunicação.

Desta feita, na sociedade contemporânea, configurada pela influência decisiva dos meios de comunicação, as culturas, os processos informacionais e as competências requeridas passam por uma crise de significados sem precedentes. Nesse sentido, torna-se evidente um destaque especial à rede mundial de computadores, conhecida como Internet, e aos programas de computador que viabilizam a comunicação e a interatividade com ela. Tais programas estão abrindo espaço para novas relações e valores entre as pessoas, disponibilizando um fluxo de informações em diversos níveis, assim como potencializando o acesso a outros mundos, por meio do ciberespaço.

Nesse sentido, Rosenberg (2002) afirma que, nesse novo meio de comunicação, há a convergência de várias mídias digitais, que podem ser interligadas e elaboradas conjuntamente, configurando uma nova linguagem e um novo espaço de comunicação. Consequentemente, organiza-se a construção de uma nova ordem social baseada nessas tecnologias, como a cibercultura, correspondente a um "[...] conjunto de técnicas (materiais e intelectuais), de práticas, de atitudes, de modos de pensamento e de valores que se desenvolvem juntamente com o crescimento do ciberespaço" (Levy, 2000, p.17). Em pesquisas anteriores, Lévy sinaliza a abrangência do ciberespaço como um espaço de troca de conhecimento e comunicação aberta,

[...] o ciberespaço, dispositivo de comunicação interativo e comunitário, apresenta-se justamente como um dos instrumentos privilegiados da inteligência coletiva [...] os pesquisadores e estudantes do mundo inteiro trocam ideias, artigos, imagens, experiências ou observações [...]. O especialista de uma tecnologia ajuda um novato, enquanto um outro especialista o inicia, por sua vez, em campo no qual ele não tem conhecimento (Levy, 1999, p.29).

A comunicação interativa e comunitária no ciberespaço mostra-se como um espaço da sociedade em rede, definindo novas formas de relações e condicionando o indivíduo a entendê-lo como uma questão distante de sua realidade física. Para Silva Neto e Maciel (2010, p.10), o ciberespaço é "[...] apresentado como um meio impalpável, imaterial e desterritorializado. Justamente porque é um lugar abstrato, invisível e semiótico, onde acontecem fluxos de informações na forma de sons, imagens, textos, entre outros". Esse é um território que possibilita interações simbólicas interpessoais, a partir dos mais variados lugares do mundo.

Frente a esse cenário, e partindo do pressuposto de que o ciberespaço (assim como a narrativa) é um lugar privilegiado só passível de fechamento através de um leitor (Ricoeur, 1994), instaura-se a preocupação com o registro e a conservação da memória, em meio virtual, de todo esse aparato informacional depositado no ciberespaço. Segundo Le Goff (2003, p.471), pela memória tem-se a propriedade de conservar certas informações, dado que ela "[...] procura salvar o passado para servir ao presente e ao futuro [...]". Explicam-se tais preocupações pelo fato de o homem contemporâneo viver numa sociedade que se constrói por influência deliberada dos meios e processos de comunicação, o que pode comprometer a memória coletiva, não viabilizando o processo de "[...] trabalhar de forma que a memória coletiva sirva para a libertação e não para a servidão dos homens" (Le Goff, 2003, p.471).

Presume-se que os aspectos que permitem aos seres humanos se tornarem livres para dispor de suas próprias memórias e cultura no ciberespaço, bem como para se beneficiarem do conhecimento e das aptidões de outros, envolvem algum tipo de sistema de armazenamento para transmitir, conservar e armazenar a memória através dos tempos.

Essa representação informacional no ciberespaço, que é um ambiente multimodal, caracterizado pela atualização frequente de informações, necessita de processos em que os usuários atualizem e transformem 
seus conhecimentos. Nesse sentido, recorre-se a Cassirer (1986), que estabelece que o conhecimento traz a ideia de processo, de sistema em constante atualização, não estanque nem parado. Isso será possível graças à capacidade cognitiva e à habilidade de exercitar o conhecimento e a imaginação, mencionada por Bronowski (1997) como uma das mais importantes capacidades do ser humano.

Assim, segundo Thompson (1998), as pessoas passam a considerar cada vez mais outras fontes de informação, além das pessoas com as quais interagem diretamente no cotidiano, destacando-se que a criação e a renovação das tradições são processos que se tornam sempre mais interligados ao intercâmbio simbólico mediado.

É nesse contexto que

Os mecanismos de busca no ciberespaço têm grande importância [para a] memória, pois realizam "lembranças" dos conteúdos que lá estão. Entretanto, eles não atuam na Internet "invisível", onde grandes quantidades de dados não são acessíveis aos indivíduos. Para se ter uma ideia, o Google, hoje, é uma das maiores plataformas de processamento de dados do mundo, entretanto, seu objetivo é a busca e não a preservação dessa memória (Monteiro et al., 2006, p.11).

Convém ressaltar que o aumento exacerbado do volume e do fluxo de informações no ciberespaço, conjugado com a inaptidão de transformar essa informação em conhecimento, tem trazido sérios desafios a usuários e produtores, colocando os profissionais da informação na condição de se indagarem sobre qual a condição básica de preparo para ofertar continuidade ao armazenamento e à conservação da memória na sociedade contemporânea.

As palavras de Candau (2011, p.195) podem sugerir uma alterativa, se aceito o fato de ter-se que fazer escolhas das memórias a serem guardadas:

[...] reconhecer que a totalidade das memórias nos é inacessível, admitir nossa radical individualidade e a impossibilidade definitiva de um compartilhamento absoluto com o Outro é, talvez, a única maneira de reconstituir as memórias que não serão mais hegemônicas, mas pelo menos sólidas e organizadoras de um laço social em condições de repudiar toda ideia de submissão.
Tal afirmação não sugere um individualismo ou ausência de disseminação da informação no ciberespaço, mas um profundo processo de seleção da informação que seja pertinente e precisa. Com isso, o cientista da informação pode desempenhar papel estratégico nos processos de organização, acesso e uso do conteúdo informacional. Metodologias como as análises de redes sociais nos estudos de fluxo e transferência da informação, por exemplo, podem ser mecanismos úteis na potencialização das habilidades dos agentes envolvidos e no seu acesso às informações e à construção do conhecimento. Desse modo, poder-se-iam perceber os efeitos das redes para além de seu próprio espaço, nas interações com a sociedade mais ampla, o Estado ou outras instituições significativas, onde as decisões micro são influenciadas pelo macro, tendo a rede como intermediária (Marteleto, 2001).

\section{Métodos}

Os textos compilados nos trabalhos apresentados no Encontro Nacional de Pesquisa em Ciência da Informação (ENANCIB) do GT - 10 reúnem autores cujo interesse repousa na temática sobre a relação entre Informação e Memória. Os ensaios cobrem os anos de 2010 e 2011. Foram analisados 70 artigos (36 deles publicados nos Anais de 2010 e 34 nos Anais de 2011), selecionando-se aqueles que trabalharam com a temática informação e memória no ciberespaço.

Para isso, selecionaram-se os trabalhos através de análises prévias dos títulos, resumos, palavras-chave e tópicos que os compunham. Fez-se uso do método booleano (e/ou) com os seguintes descritores: informação, memória, ciberespaço, cultura digital, cibercultura e ambiente virtual. Observou-se que o uso somente dos descritores informação e memória não era de interesse para o contexto da pesquisa, pois se buscavam convergências com o ciberespaço.

Essa técnica de análise documentária é muito utilizada na área de Biblioteconomia para indexação de documentos, como forma norteadora para indexação e recuperação da informação. Após a identificação de quais documentos eram mais pertinentes, realizou-se uma leitura dinâmica de todo o conteúdo dos artigos selecionados, a fim de analisar qual o objetivo e problemática trabalhados nas pesquisas e, assim, promover uma leitura crítica sobre o objeto de estudo. 
Do conjunto dos 70 trabalhos analisados verificou-se que todos os artigos, alguns de forma mais complexa que outros, tratavam sobre informação e memória. No entanto, somente 13 artigos abordavam questões intrinsecamente relacionadas à informação e à memória no ciberespaço, sendo oito trabalhos nos Anais de 2010, e cinco trabalhos nos Anais de 2011.

Desse modo, foi realizado um exame de cada um dos artigos que indicavam estar relacionados aos três construtos que servem de pilar a este estudo e que contribuíram para analisar, de maneira prévia, como está a discussão sobre os problemas que cercam a informação e memória no ciberespaço na área da $\mathrm{Cl}$.

\section{Resultados e Discussão}

Conforme apresentado, neste estudo trabalhou-se com três construtos: informação, memória e ciberespaço, temáticas que foram buscadas através de revisão bibliográfica dos trabalhos publicados nos ENANCIB de 2010 e 2011. A fim de avaliar a preocupação dos autores da Cl com o registro e a conservação da memória em meio virtual, dispõem-se em diálogo os 13 artigos, buscando-se analisar as contribuições que os pesquisadores trazem para esse novo lugar de memória em ação e transformação permanentes, conforme apontado por Menezes (2007).

Como fonte de dados, foram analisados os seguintes artigos apresentados em 2010: "Informação, memória e conhecimento: convergência de campos conceituais", de Dodebei (2010);"Memória e socialização da informação na Web", de Silva, et al. (2010); "A memória social na era das novas tecnologias", de Oliveira (2010); "De coleção virtual a acervo dinâmico", de Souza e Crippa (2010); "Ciência da Informação e museus de arte", de Catoira (2010); "Virtualização e preservação da memória social", de Henriques (2010); "Memória virtual da arte digital", de Monteiro (2010); e"Preservar o digital ou não, a questão do depósito legal", de Pinto (2010). Dos Anais de 2011, foram analisados: "O sujeito e suas redes de dizer no online", de Patti et al. (2011);"Objetos digitais em fluxo", de Oliveira et al. (2011); "Ciberhistória, cibermemória e a informação sobre o patrimônio cultural", de Oliveira (2011); "Centro de memória digital", de Valls et al. (2011); e "Uso de tecnologia intelectual digital para a preservação", de Freire et al. (2011).
Algumas questões que carecem ser levantadas nos artigos acima traçam-se a partir de um caminho investigativo sobre aspectos teórico-conceituais nos campos da Memória Social e da Cl. Nesse sentido é o pensamento de Dodebei (2010, online), que navega entre fronteiras de disciplinas até chegar à conclusão de que a Cultura Digital "[...] parece ser o encontro das águas de pequenos riachos que navegam num solo comum compartilhado pelos humanos, e a tecnologia integra a cultura desde a invenção do fogo [...]". A discussão sobre memória e informação, para a referida autora, dialoga com o conceito de acumulação e com a tensão existente entre lembrança e esquecimento - ou, como sugere Candau (2011, p.195): "[...] reconhecer que a totalidade das memórias nos é inacessível [...]"e que o processo de seleção é inevitável.

Partindo da premissa de veracidade das informações veiculadas e questionando-se sobre o que pode ser considerado patrimônio digital, Pinto (2010) e Valls et al. (2011) compreendem o ciberespaço como ambiente apropriado para que as instituições possam preservar e disseminar sua história. Ou seja, o processo de seleção, lembrança e esquecimento dialogados por Dodebei (2010) encontra reflexões objetadas por outros autores que buscam compreender a história como tema:

\footnotetext{
Hoje em dia, cada vez mais as pessoas percebem a importância de terem suas próprias histórias como tema e como essa construção de vínculos é importante para a própria auto-estima. Daí a divulgação, ou pelo menos tentativas, de retratos históricos individuais e coletivos, sistematizados ou em moldes simples, sem tratamento científico (Oliveira, 2010, p.3).
}

Na busca por encontrar lugares de memória social dentro do universo de informações presente no ambiente do ciberespaço, o autor destaca, em artigos tanto de 2010 quanto de 2011, o espaço útil e democrático da Internet e abre diálogo para a concepção que Bosi (1994, p.10) traça sobre memória:"[...] é essa reserva crescente a cada instante e que dispõe da totalidade da nossa experiência adquirida".

A discussão estabelecida nos escritos de Dodebei (2010) e Oliveira (2010; 2011) traça diferentes perspectivas sobre como compreender e valer-se do ciberespaço para a preservação da memória: selecionar ou ampliar a informação em ambientes digitais? compartilhar de forma absoluta as informações ou traçar escolhas 
no ciberespaço, entendendo que a memória é"[...] transpassada por um universo simbólico dos mais significativos, mediante um processo de representação [...]?" (Azevedo Netto, 2008, p.12).

Interligando a uma perspectiva de expansão da memória, no intuito de construir uma memória social que contemple a inclusão de determinados segmentos da sociedade, Silva et al. (2010) e Catoira (2010) destacam a importância da construção de sítios virtuais que atuem como suportes para o armazenamento e distribuição de informação. Ainda conforme Quéau (2001, p.179):

[...] não se pode deixar apenas nas mãos das forças do mercado o cuidado de regular o acesso aos conteúdos das "autovias da informação" [...] são esses conteúdos que vão tornar-se o desafio fundamental do desenvolvimento humano nos âmbitos da sociedade da informação. $O$ ciberespaço deve permitir a todos o acesso às informações e aos conhecimentos necessários para a educação e para o desenvolvimento de todos os homens.

Assim, percebe-se que, se o ciberespaço não representa uma solução inabalável para uma distribuição igualitária do conteúdo informacional e a construção de uma memória social, sem dúvida "[...] constitui uma das condições fundamentais da integração da vida social" (Sorj, 2003, p.15). Além disso, constitui um espaço para o estoque de informação das pessoas depositárias da memória social e do saber da comunidade.

Dialogando com Huyssen (2000), Henriques (2010) encampa uma linha de raciocínio acerca do excesso de memória no ciberespaço e da "explosão de esquecimento" que a Internet proporciona. Indaga-se se muitas das memórias apresentadas seriam reais ou imaginadas, prontas para serem registradas e proliferadas nos espaços digitais. Revelam-se de forma abstêmia certas preocupações quanto à preservação e à virtualização da memória social, tanto no aspecto da preservação digital daquilo que é físico, quanto na definição de critérios para selecionar o que deve ser preservado.

A proliferação ou multiplicação rápida é fonte de conjecturas de Souza e Crippa (2010), ao se referirem sobre o boom ou "explosão" da memória, que atraiu os olhares da $\mathrm{Cl}$, principalmente em decorrência do incessante interesse da modernidade pelo que aconteceu no passado. A memória, especificamente a memória social, é uma das maiores fontes de discussão nos artigos do Enancib, quando alinhada ao ciberespaço. Verifica-se em Monteiro (2010) e Oliveira et al. (2011) a relação entre memória social, patrimônio digital e ambiente virtual, como forma de preservação da memória através do acesso livre, com possibilidade de aproximar pessoas, objetos e suas memórias no tempo e espaço.

Examinando os estudos publicados nos Anais de 2010 e 2011, constata-se a aproximação que se estabelece entre memória social, disseminação da informação e ciberespaço. Para melhor examinar o construto "informação, memória e ciberespaço," recorre-se a Ricoeur (2007), com sua concepção de "testemunho": apesar da carência principal de confiabilidade, não há nada melhor que o testemunho para assegurar o indivíduo de que algo aconteceu, já que alguém atesta tê-lo assistido pessoalmente. Ou seja, percebe-se que, para a promoção do testemunho de uma comunidade, para o registro em um espaço e tempo de existência de um acontecimento que evoque a lembrança de um passado, o espaço virtual tornou-se, na visão de alguns autores da $\mathrm{Cl}$, um grande propagador da memória social. Nesse aspecto, joeirar a informação não é o objetivo principal, segundo alguns pesquisadores.

Dialogando com Patti et al. (2011), conclui-se que o que prevalece é o discurso do sujeito na rede eletrônica, sua linguagem e as questões que constituem esse sujeito navegador e não propriamente a seleção daquilo que é dito. Assim, por meio das análises realizadas nas 13 obras, publicadas por 21 autores de forma colaborativa ou individual, constou-se um esforço coletivo, nos dois primeiros anos do GT (10), para a consolidação dos estudos sobre informação, memória e ciberespaço. As discussões, empreendidas sob uma variedade de perspectivas tanto sociais quanto culturais, apontaram o ciberespaço como um ambiente para a organização e a memória do conhecimento.

Verificou-se que diversos autores destacaram o ciberespaço como um facilitador informacional e espaço de integração da vida social. Porém eles, principalmente, enfatizaram a visão de que o ciberespaço é um ambiente apropriado para a construção, preservação e disseminação da memória social e coletiva, com a vantagem do acesso livre, como observado por Silva et al. (2010, p.1): "[....] de acesso livre na Internet, o sítio virtual constitui a representação do tesouro de conhecimentos das pessoas depositárias da memória social e do saber [...]". 


\section{Conclusão}

Por meio dos artigos analisados, percebe-se que o ciberespaço apresentou-se como um grande facilitador da memória social e um tesouro para a preservação da memória. Por outro lado, são menos frequentes os estudos sobre a seleção das informações, sobre a tensão entre lembrança versus esquecimento, e sobre a veracidade da informação e da memória veiculadas no ciberespaço.

Com isso, as inquietações mencionadas por alguns dos autores da área da $\mathrm{Cl}$ demonstram possíveis problemas que podem afetar a questão da memória no ambiente virtual, tais como o esquecimento, aspecto de certa forma alertado, conforme citado anteriormente. A independência do registro produzido pelo homem, sendo um produto de confecção humana, é uma fonte de aflição e inquietação quando se trata da memória social. Além disso, a questão da veracidade das informações produzidas no ambiente virtual também demonstra a complexidade e subjetividade do artefato informação.

Afirma-se que facilidade do acesso, principalmente no meio virtual, e a eliminação dos esforços cognitivos resultam, de forma geral, em uma informação desprovida de atributos, dificultando a assimilação; o que está em jogo é a tentativa de livrar o homem do esforço de lembrar.

\section{Referências}

Azevedo Netto, C.X. Informação e memória: as relações na pesquisa. História em Reflexão, Dourados, v.1, n.2, p.1-20, 2007.

Azevedo Netto, C.X.Preservação do patrimônio arqueológico: reflexões através do registro e transferência da informação. Ciência da Informação, v.37, n.3, p.7-17, 2008.

Bawden, D.; Robinson, L. The dark side of information: Overload, anxiety and other paradoxes and pathologies. Journal of Information Science, v.35, n.2, p.180-191, 2009.

Bosi, E. Memória e sociedade: lembranças de velhos. São Paulo: Companha das Letras, 1994.

Braga, R. O excesso de informação: a neurose do século XXI. 2006. Disponível em: <http://www.mettodo.com.br/pdf/ O\%20Excesso\%20de\%20Informacao.pdf>. Acesso em: 20 jul. 2012.

Bronowski, J. As origens do conhecimento e a da imaginação. Brasília: UnB, 1997.
Diante do estudo realizado, se para alguns autores selecionar é uma condição determinante no processo de construção da memória - seja ela individual, coletiva, ou virtual -, compreende-se que, em se tratando do meio virtual ou ciberespaço, desmistificar a noção de que a informação seria objetiva incorre na necessidade de se (re)pensar a forma como ela é tratada, de maneira quantificada e uniformizada.

A partir desses pressupostos, busca-se elucidar que a $\mathrm{Cl}$ tem muito a contribuir naquilo que concerne à seleção da informação disponibilizada, para o que se pretende construir uma cadeia relacional de significados, com um instrumental lógico. Frente à discussão teórica e à análise empírica explanada no trabalho, considera-se que o ciberespaço pode proporcionar a preservação da memória individual, social e coletiva, mediante manifestações e ações afirmativas dos profissionais da $\mathrm{Cl}$, em prol da conservação e registro da informação.

Destarte, espera-se que pesquisas venham a contemplar essas discussões acerca da problemática de memória e informação no ciberespaço, pois as considerações aqui realizadas restringem-se aos Anais dos Enancib, podendo tal trabalho ser ampliado por meio de outras investigações. Assim, aspira-se que essa temática faça cada vez mais parte do cenário acadêmico da $\mathrm{Cl}$, pois se presume que a cibercultura é uma das maiores manifestações culturais que a humanidade já presenciou ao longo de todo seu desenvolvimento.

Candau, J. Memória e identidade. São Paulo: Contexto, 2011.

Cassirer, E. El problema del conocimiento en la filosofia y en la ciencia modernas. México: Fondo de Cultura Econômica, 1986.

Catoira, T. Ciência da Informação e museus de arte: diálogos e interações no acesso às informações do acervo do núcleo de arte contemporânea da Paraíba. In: Encontro Nacional de Pesquisa em Ciência da Informação, 11., 2010, Rio de Janeiro. Anais eletrônicos... Rio de Janeiro: Ancib, 2010. Disponível em: <http://congresso.ibict.br/index.php/xi/enancibXI/paper/ view/242/163>. Acesso em: 7 maio 2012.

Dodebei, V.L.D.L.M. Informação, memória, conhecimento: convergência de campos conceituais. In: Encontro Nacional de Pesquisa em Ciência da Informação, 11., 2010, Rio de Janeiro. Anais eletrônicos... Rio de Janeiro: Ancib, 2010. Disponível em: <http://congresso.ibict.br/index. php/xi/ enancibXI/paper/view/242/163 >. Acesso em: 7 maio 2012.

Freire, I.M.; Farias, M.G.G.; Silva, P. Uso de tecnologia intelectual digital para a preservação da memória da comunidade Santa 
Clara. In: Encontro Nacional de Pesquisa em Ciência da Informação, 12., 2011, Brasília. Anais... Brasília: UnB, 2011. p.1-20.

Habermas, J. Passado como futuro. Rio de Janeiro: Tempo Brasileiro, 1993.

Henriques, R.M.N. Virtualização e preservação da memória social: o caso do Museu da Pessoa. In: Encontro Nacional de Pesquisa em Ciência da Informação, 11., 2010, Rio de Janeiro. Anais eletrônicos... Rio de Janeiro: Ancib, 2010. Disponível em: <http://congresso.ibict.br/index.php/xi/enancibXI/paper/ view/242/163>. Acesso em: 7 maio 2012.

Huyssen, A. Seduzidos pela memória. Rio de Janeiro: Aeroplano, 2000.

Le Goff, J. História e memória. 5.ed. Campinas: Unicamp, 2003.

Lévy, P. Cibercultura. São Paulo: Editora 34, 1999.

Lévy, P. Cibercultura. São Paulo: Editora 34, 2000.

Marteleto, R.M. Análise de redes sociais: aplicação nos estudos de transferência da informação. Ciência da Informação, v.30, n.1, p.71-81, 2001.

Marx, K.; Engels, F. A Ideologia em geral e particularmente a alemã. In: Marx, K.; Engels, F. A ideologia alemã. São Paulo: Martin Claret, 2006. p.7-54.

Menezes, U.B. Os paradoxos da memória. In: Miranda, D.S. Memória e cultura: a importância na formação cultural humana. São Paulo: Sesc, 2007. p.13-33.

Mikhailov, A.I. Information in a developing world. International Forum on Information and Documentation, v.9, n.3, p.1-2, 1984.

Monteiro, E.C.C. Memória virtual da arte digital. In: Encontro Nacional de Pesquisa em Ciência da Informação, 11., 2010, Rio de Janeiro. Anais eletrônicos... Rio de Janeiro: Ancib, 2010. Disponível em: <http://congresso.ibict.br/index.php/xi/ enancibXI/paper/view/242/163 > . Acesso em: 7 maio 2012.

Monteiro, S.; Carelli, A.; Pickler, M. Representação e memória no ciberespaço. Ciência da Informação, v.35, n.3, p.115-123, 2006. Disponível em: <http://revista.ibict.br/ciinf/index. php/ ciinf/article/view/704/596/>. Acesso em: 25 jul. 2012.

Oliveira, J.C. A memória social na era das novas tecnologias. In: Encontro Nacional de Pesquisa em Ciência da Informação, 11., 2010, Rio de Janeiro. Anais eletrônicos... Rio de Janeiro: Ancib, 2010. Disponível em: <http://congresso.ibict.br/ index.php/xi/enancibXI/paper/view/242/163>. Acesso em: 7 maio 2012

Oliveira, J.C. Ciberhistória, cibermemória e a informação sobre o patrimônio cultural. In: Encontro Nacional de Pesquisa em Ciência da Informação, 12., 2011, Brasília. Anais eletrônicos... Brasília: UnB/Ancib, 2011. Disponível em: <http://congresso. ibict.br/index.php/xi/enancibXI/paper/view/242/163>. Acesso em: 7 maio 2012.

Oliveira, M.C.G.; Malta, A.O.L.; Gouveia Júnior, M.Objetos digitais em fluxo: a virtualização de acervos museológicos garante o acesso e a aplicação social da informação patrimonial? In: Encontro Nacional de Pesquisa em Ciência da Informação, 12., 2011, Brasília. Anais eletrônicos... Brasília: UnB, 2011. Dispo- nível em: <http://congresso.ibict.br/index.php/xi/enancibXI/ paper/view/242/163>. Acesso em: 7 maio 2012.

Pacheco, L.M.S. Informação enquanto artefato. Informare: Cadernos do Programa de Pós-Graduação em Ciência da Informação, v.1, n.1, p.20-24, 1995.

Patti, A.R.; Giorgenon, D.; Romã, L.M.S. O sujeito e suas redes de dizer no on-line. In: Encontro Nacional de Pesquisa em Ciência da Informação, 12., 2011, Brasília. Anais eletrônicos... Brasília: UnB, 2011. Disponível em: <http://congresso. ibict.br/ index.php/xi/enancibXI/paper/view/242/163>. Acesso em: 7 maio 2012.

Pinto, M.R.S. Preservar o digital ou não, a questão do depósito legal. In: Encontro Nacional de Pesquisa em Ciência da Informação, 11., 2010, Rio de Janeiro. Anais eletrônicos... Rio de Janeiro: Ancib, 2010. Disponível em: <http://congresso. ibict.br/index.php/xi/enancibXI/paper/view/242/163>. Acesso em: 7 maio 2012.

Quéau, P. Cibercultura e info-ética. In: Morin, E. (Org.). A religação dos saberes: o desafio do século XXI. Rio de Janeiro: Bertrand Brasil, 2001. p.460-480.

Ricoeur, P. Tempo e narrativa. Tomo I. São Paulo: Papirus Editora, 1994.

Ricoeur, P. A memória, a história, o esquecimento. Campinas: Unicamp, 2007.

Rosenberg, M. E-Learning. São Paulo: Makron Books, 2002.

Silva, P.; Freire, I.M.; Farias, M.G.G. Memória e socialização da informação na web. In: Encontro Nacional de Pesquisa em Ciência da Informação, 11., 2010, Rio de Janeiro. Anais eletrônicos... Rio de Janeiro: Ancib, 2010. Disponível em: <http:/ /congresso.ibict.br/index.php/xi/enancibXI/paper/view/242/ 163>. Acesso em: 7 maio 2012.

Silva Neto, C.E.; Maciel, J.W.G. A era dos sistemas inteligentes: o hipertexto como ferramenta ciberespacial em arquivos. In: Simpósio Hipertexto e Tecnologias na Educação, 3., 2010, Recife. Anais eletrônicos... Recife: UFPE, 2010. Disponível em: <http://congresso.ibict.br/index.php/xi/enancibXI/paper/ view/242/163>. Acesso em: 7 maio 2012.

Sorj, B.Brasil@povo.com: a luta contra a desigualdade na sociedade da informação. Rio de Janeiro: Jorge Zahar, 2003.

Souza, E.D. Dimensões teórico-metodológicas da Ciência da Informação: dos desafios à consolidação Epistemológica. In: Encontro Nacional de Pesquisa em Ciência da Informação, 9., 2008, São Paulo. Anais eletrônicos... São Paulo: USP, 2008. Disponível em: <http://repositorios.questoesem rede.uff.br/ repositorios/bitstream/handle/123456789/1017/Dimens\% C3\%B5es.pdf?sequence=1 >. Acesso em: 10 jan. 2012.

Souza, W.E.R.; Crippa, G. De coleção virtual a acervo dinâmico: o patrimônio e seu valor informacional. In: Encontro Nacional de Pesquisa em Ciência da Informação, 11., 2010, Rio de Janeiro. Anais eletrônicos... Rio de Janeiro: Ancib, 2010. Disponível em: <http://congresso.ibict.br/index.php/xi/enancibXI/ paper/view/242/163>. Acesso em: 7 maio 2012.

Thompson, J. A mídia e a modernidade: uma teoria social da mídia. Petrópolis: Vozes, 1998. 
Valls, V.M.; Rueda, V.M.S.; Freitas, A. Centro de memória digital: estabelecimento de critérios para a sua implantação. In: Encontro Nacional de Pesquisa em Ciência da Informação, 12., 2011, Brasília. Anais eletrônicos... Brasília: UnB, 2011. Disponível em: <http://repositorios.questoesemrede.uff.br/ repositorios/bitstream/handle/123456789/2195/Centro\%20\%20Valls.pdf?sequence=1 >.Acesso em: 10 jan. 2012.
Wurman, R.S. Ansiedade de informação 2: um guia para quem comunica e dá instruções. São Paulo: Cultura, 2005.

Zeman, J. Significado filosófico da noção de informação. In: Zeman, J. O conceito de informação na ciência contemporânea. Rio de Janeiro: Paz e Terra, 1970. p.154-179. (Série Ciência da Informação, 2). 